Boise State University

ScholarWorks

$1-2-2002$

Depth Characterization of Shallow Aquifers with Seismic Reflection, Part II-Prestack Depth Migration and Field Examples

John H. Bradford

Boise State University

D. S. Sawyer

Rice University 


\title{
Depth characterization of shallow aquifers with seismic reflection, Part II-Prestack depth migration and field examples
}

\author{
John H. Bradford* and D. S. Sawyer
}

\begin{abstract}
It is common in shallow seismic studies for the compressional-wave velocity in unconsolidated sediments to increase by a factor of four or more at the transition from dry or partial water saturation to full saturation. Under these conditions, conventional NMO velocity analysis fails and leads to large depth and layer thickness estimates if the Dix equation is assumed valid. Prestack depth migration (PSDM) is a means of improving image accuracy. A comparison of PSDM with conventional NMO processing for three field examples from differing hydrogeologic environments illustrates that PSDM can significantly improve image quality and accuracy.
\end{abstract}

\section{INTRODUCTION}

It is common for the compressional-wave velocity to increase by a factor of four or more where shallow, unconsolidated sediments change from a dry or partially water-saturated regime to full saturation. We refer to this transitional boundary as the water table $(W)$, recognizing that full water saturation actually occurs slightly above the water table because of capillary forces. The occurrence of a large vertical velocity contrast is a relatively common scenario in shallow seismic reflection where, in a single study, we may be interested in imaging features both above and below the water table. The extreme velocity gradient violates many of the assumptions made in conventional reflection data processing schemes. In a companion paper, Bradford (2002) discusses the severe errors in depth and layer thickness estimates that can result when interval velocities are obtained with NMO velocity analysis and Dix inversion. NMO processing can provide an acceptable image in time, but there are significant problems with data distortion when trying to image features both above and below the water table.
Miller (1992) and Miller and Xia (1998) discussed this problem but do not address the depth prediction errors inherent in the method.

The optimum window (Hunter et al., 1984) in which to observe reflections above the saturated zone typically occurs at much smaller offsets than the window for observing reflections below the water table. If we are interested only in targets below the water table, we may acquire relatively long offset data to avoid near-offset problems with surface-related noise. In this case, we have little or no velocity control for the shallowest part of the section, and stacking velocities are measured only from reflections originating beneath the water table. Often such a stacking velocity function will appear well behaved (no large gradients and gradual increase with depth), and there will be no obvious indication of the large velocity gradient. Naively assuming that a well-behaved stacking velocity profile indicates the validity of the NMO assumption can lead to severe errors in depth prediction and incorrect data interpretations (Bradford, 2002). We must consider the low-velocity portion of the velocity field to accurately predict the subsurface.

For a typical velocity profile across the water table, stacking velocity $\left(v_{s t k}\right)$ is significantly larger than rms velocity $\left(v_{r m s}\right)$ for reflections within about the first $30 \mathrm{~m}$ of the saturated zone. This leads to significant depth prediction errors if the Dix equation is assumed valid. The problem is exaggerated in the shallow environment because extremely low $\mathrm{S} / \mathrm{N}$ ratios in the near-offset regime often require recording reflections at large offset-todepth ratios (Hunter et al., 1984; Baker et al., 1998; Bradford, 2002). Stacking velocity increases with increasing offset range, leading to greater divergence from the NMO assumption.

When conventional velocity analysis fails, we must resort to prestack depth migration (PSDM) velocity analysis or inverse methods. We typically think of PSDM as only necessary for laterally heterogeneous velocity fields; however, it is also necessary when the vertical velocity gradient is very large. While there are less computationally intensive methods of obtaining accurate velocity-depth profiles, PSDM will provide the most accurate and detailed images.

Manuscript received by the Editor December 21, 1998; revised manuscript received November 21, 2000.

*Formerly Rice University, Department of Geology and Geophysics, Houston, Texas 77005; presently Boise State University, CGISS, 1910 University Drive, Boise, Idaho 83725. E-mail: johnb@cgiss.boisestate.edu.

$\ddagger$ Rice University, Department of Geology and Geophysics, 6100 Main St., Houston, Texas 77005-1892. E-mail: dale@rice.edu.

(C) 2002 Society of Exploration Geophysicists. All rights reserved. 
In this paper, we first discuss improving image accuracy through alternative processing schemes with a focus on PSDM. We complete the discussion with three field examples from differing hydrogeologic environments that illustrate some problems and benefits of PSDM.

\section{PROCESSING STRATEGIES}

In a companion paper, Bradford (2002) shows that conventional velocity analysis can lead to overestimating interval velocity by $10 \%$ to more than $100 \%$ when the water-saturated layer is less than about $30 \mathrm{~m}$ thick. To improve depth and layer thickness estimates, we must pursue alternative processing strategies or, at a minimum, estimate the bias in our prediction.

Al-Chalabi (1974) presents three methods of improving interval velocity estimates: (1) model simulation, (2) three-term stack, and (3) method of shifting stack. Model simulation is essentially a precursor of modern inversion methods. The three-term stack is not an appropriate option in the case under consideration because of rapid divergence of the three-term truncation of Taner and Koehler's (1969) infinite series representation of the traveltime equation. Divergence of the threeterm series is related to the severe velocity gradient coupled with the need for relatively large offset-to-depth ratios.

The method of shifting stack is a simple, graphical method of estimating velocity bias, but it requires good reflection quality over a significant range of offsets. To apply this method, first calculate stacking velocities over several discreet offset intervals. Then construct a plot of $x_{\text {avg }}$ versus $v_{s t k}^{2}$ (where $x_{\text {avg }}$ is the average offset of the interval over which $v_{s t k}$ is calculated) and extrapolate to find $v_{s t k}$ at zero offset $\left(\left.v_{s t k}\right|_{x=0}=v_{r m s}\right)$. With the correct value of $v_{r m s}$, we can accurately compute the interval velocity using Dix inversion.

\section{Prestack depth migration}

Ultimately we would like to use a processing scheme that does not depend on the approximations of conventional processing. Inverse methods can provide an accurate description of the gross velocity structure, but they lack detail since only a few key interfaces are used in the analysis. PSDM is the most accurate and detailed imaging method; we focus on this method as a means of improving depth and layer thickness estimates.

The accuracy of the migration depends on an accurate and detailed velocity model which must be obtained using an inverse method and/or PSDM velocity analysis. PSDM velocity analysis (Al-Yahya, 1989; Rajasekaran and McMechan, 1992; Lafond and Levander, 1993; Liu, 1997) involves an iterative approach in which the velocity model is updated from the top down. The velocity model is correct (to the extent that wavefield kinematics are accurately estimated) when reflectors in common image point (CIP) gathers [the PSDM analog to common midpoint (CMP) gathers] are flattened. The starting model for PSDM velocity analysis may be estimated using a variety of methods. We suggest three methods that progress from relatively simple to relatively complex and computationally intensive.

Method 1: The two-layer model.-The simplest starting model is a two-layer, 1-D model. The upper layer is constant velocity estimated from the moveout of the water table reflection and/or the direct arrival. The second layer has a linear velocity gradient with the velocity at the top of the layer estimated from the moveout of the water table refraction. We estimate the gradient in the second layer in the following way. First, calculate the stacking velocity of a reflector that is much deeper $(>30 \mathrm{~m})$ than the water table; then estimate the interval velocity using Dix inversion. Assuming the Dix interval velocity is approximately equal to the average interval velocity, adjust the velocity gradient in the starting model so that average velocity in the second layer matches the Dix interval velocity. This method generally works well when the velocity function is one dimensional and the heterogeneity above and below the water table is minimal. The coastal plain example in the case studies section, shows how this method is used.

Method 2: NMO analysis and the method of shifting stack.This method is effective when there is significant heterogeneity above or below the water table and if the velocity field varies horizontally. In this approach, one uses the method of shifting stack to estimate the rms velocity function at key CMPs. The interval velocities can then be estimated using Dix inversion. This method provides a reasonably accurate and detailed velocity model with minimal computation requirements as long as lateral velocity variation is greater than a spread length.

Method 3: Traveltime inversion.--Inverse methods provide the most accurate starting model and work with relatively complex velocity fields that vary vertically and horizontally. We use Zelt and Smith's (1992) inversion code, which relies on an arbitrary combination of traveltime picks of turning waves, refractions, and reflections. The velocity model output using inverse methods should be very close to the final migration velocity model but may require fine-tuning. The fluvial and coastal environment field examples illustrate how inversion is used to estimate the starting model.

Additional considerations. - In PSDM processing, refractions can migrate and stack coherently, appearing as reflections in the final image and leading to misinterpretation. The problem is analogous to stacking refractions in conventional NMO processing, where it has been recognized as a major pitfall (Steeples and Miller, 1990, 1998). Additionally, migrating high-amplitude noise within the noise cone will severely degrade the $\mathrm{S} / \mathrm{N}$ ratio in the final processed image. Prior to PSDM, the data should follow the same noise suppression scheme as followed for NMO processing. This includes muting the first break and refractions [although under certain conditions acceptable results may be obtained if this step is bypassed (Pasasa et al., 1998)] and attenuating the noise cone with any of the commonly used approaches, including $f-k$ filtering and inside muting (Baker et al., 1998).

We migrated all data using a Kirchhoff PSDM algorithm. The data were migrated in the common-offset domain and resorted to CIP gathers for velocity analysis and stacking. The Promax ${ }^{\mathrm{TM}}$ software optionally computed the Green's function using a ray-tracing algorithm or a finite-difference solution to the eikonal equation. We carried out a number of synthetic tests and found that for the specific case of a large vertical velocity discontinuity, the finite-difference solution produced the most accurate migration result. Consequently, we used the 
finite-difference method of computing the Green's function in all migrations presented here.

On a typical field record, the energy traveling at low velocity above the water-saturated zone has a relatively steep slope and is confined to the near-offset regime, whereas compressional wave energy that travels below the water table has a relatively shallow slope and is observed at relatively large offsets. This implies that the optimum reflection window (Hunter et al., 1984) differs significantly for the two regions. For purposes of the discussion that follows, we define low-velocity field as the energy traveling at or below the highest compressional wave velocity above the water table. The high-velocity field is compressional wave energy that has some portion of its travel path within the saturated zone and therefore has high velocity moveout with a traveltime slope that becomes parallel to, or shallower than, the water table refraction at far offsets. Although this natural division of energy can present significant problems for conventional processing streams, it is possible to devise a processing strategy to produce a good image of the low- and high-velocity fields in a single survey.

Migration velocity analysis is best implemented by migrating in the common-offset domain and then resorting to CIPs for velocity analysis. This avoids edge effects typically associated with migration in the shot domain (the edge effects are effectively eliminated after stacking). However, for shallow reflection studies with a large velocity increase across the water table, problems associated with migration in the common-offset domain complicate the velocity analysis. Consider a commonoffset section where the offset-to-depth ratio for the water table reflection is relatively large so that energy from the water table reflection arrives later than energy from deeper reflections. The traveltime for the water table reflection is consistent with either the water table reflection at a depth $d_{w}$ or a reflection within the saturated zone with apparent depth $z_{a p p}$. In other words, the traveltime solution is nonunique. In the commonoffset domain there isn't enough information to determine if the reflector originates at $d_{w}$ or $z_{a p p}$. After migration in the common-offset domain, wide-aperture energy from the water table reflection remains as coherent noise at depths greater than $d_{w}$. The apparent depth $z_{a p p}$ is different for each offset and the noise is attenuated when the CIPs are stacked, resulting in a clear final image. However, in the unstacked CIPs the noise interferes with deeper reflections, which complicates interpretation for velocity analysis. Note that migration in the shot domain uses information from multiple offsets, so the problem discussed above is not an issue.

Muting the wide-aperture tails of $W$ prior to migration yields a better $\mathrm{S} / \mathrm{N}$ ratio in the final image and improves interpretability of the CIPs. The drawback to this approach is that the fold for $W$ can be very low, particularly if the survey is relatively coarse, and the smallest offset traces cannot be used because of ground roll or other coherent noise. However, if the data quality is good, this will produce acceptable results.

A second alternative is a two-pass processing strategy. We migrate the low- and high-velocity fields separately and image the full section with a single survey. A similar two-pass approach based on the natural separation of high- and lowvelocity fields is recommended by Miller and Xia (1998) for NMO processing. In this approach, the low-velocity field is isolated by applying an outside mute. The data are then migrated with a modified velocity field in which the velocity is held con- stant across and well below $W$ (although we should account for velocity variations above $W$ ). This places the wide-aperture tails of $W$ in the correct spatial location (Bradford, 1998). The high-velocity field is isolated by applying an inside mute and then is migrated with the full velocity field. The two images can be combined after migration. If minimal velocity heterogeneity exists above the water table, we can minimize computation time using a conventional NMO processing stream for the lowvelocity field and PSDM only for the deeper part of the section. The two-pass approach can produce excellent results, but data will be lost if deep primary reflections can be identified within the $W$ traveltime curve.

As the angle of incidence increases, the vertical wavenumber decreases and there is a corresponding loss of resolution (Levin, 1998). This effect is manifested as wavelet stretch at far offsets in a depth migrated section. To produce an acceptable image, we must pick a top mute where the wavelet stretch is too large. This is analogous to NMO stretch muting. An additional problem with wavelet stretch arises from the sharp velocity contrast across the water table. If the velocity boundary is placed too shallow, part of the $W$ wavelet will migrate in the high-velocity zone and will be stretched significantly. This is purely an artifact related to inaccuracy in the velocity model and a longer wavelength associated with higher velocity. The migration result is extremely sensitive to positioning of the velocity boundary, and a good result requires very detailed velocity analysis. This problem also precludes significant smoothing of the velocity field. In our experience, smoothing the field over less than a wavelength at the unsaturated velocity, gives reasonable migration results and maintains precision in placement of the $W$ reflection.

Another problem arises when we consider that some or all of the energy associated with $W$ is postcritical. In a typical case where the saturated-to-unsaturated-velocity ratio is $1: 4$, the critical angle is only $14.5^{\circ}$. If the water table is at a depth of $10 \mathrm{~m}$, we reach $\theta_{c}$ at on offset of only $5.2 \mathrm{~m}$. Often, primary energy from $W$ cannot be extracted within the precritical aperture because of coherent surface noise. A phase rotation is associated with the postcritical reflection, but the shape of the traveltime curve is still approximately hyperbolic. If the peaks or troughs of adjacent wavelets with variable-phase rotation are aligned, the apparent migration and stacking velocities will be incorrect. This error is generally very small so that velocity analysis, without phase deconvolution, results in minimal error.

\section{FIELD EXAMPLES}

We now discuss three field examples from differing hydrogeologic environments (Figure 1):

1) fluvial environment, Burleson County, Texas $\left(d_{W}=9 \mathrm{~m}\right)$;

2) coastal plain environment, Houston, Texas $\left(d_{W}=6 \mathrm{~m}\right)$; and

3) coastal environment, Bolivar Peninsula, Texas $\left(d_{W}=\right.$ $3 \mathrm{~m})$.

Each of the data sets was acquired using a 60-channel seismograph and a 120 -station cable spread with single $28-\mathrm{Hz}$ geophones. Two modes of acquisition were used: (1) roll-along/ static shoot-through (RAST) combination and (2) standard roll-along technique. In the RAST method, the 120-station 
cable spread is held static for the experiment. For the first 60 shots, the data are acquired with a standard roll-along procedure in either off-end or split-spread mode. The recording stations are incremented until the live spread corresponds to receiver stations $61-120$. For the final 60 shots, stations $61-120$ are live and are held static as we shoot through the spread. This acquisition procedure divides the profile into a 30 -fold roll-along section and a 60-fold RAST section (Figure 2). This is a convenient procedure for small-scale experiments since we can smoothly vary several acquisition parameters along the line (gap, minimum and maximum offset, and spread geometry, i.e., symmetric or asymmetric split-spread, off-end). In all of the depth migration examples that follow, we use a 2-D prestack Kirchhoff algorithm. All Dix inversion velocity profiles are calculated using a smoothed Dix inversion algorithm.

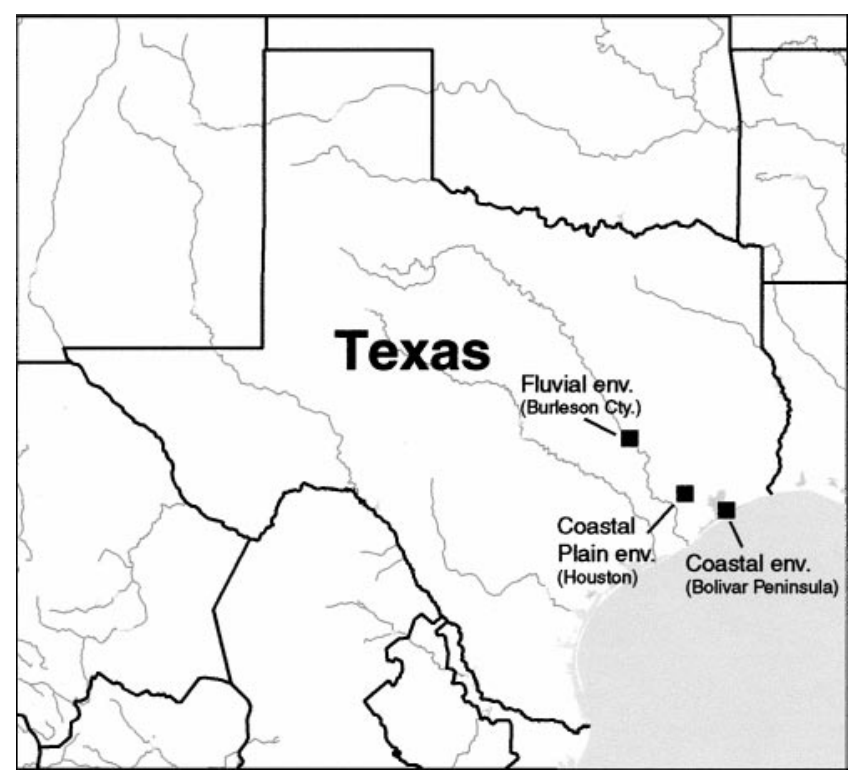

FIG. 1. Location of the three field studies discussed in this paper. The areas represent differing sedimentary and hydrologic environments.

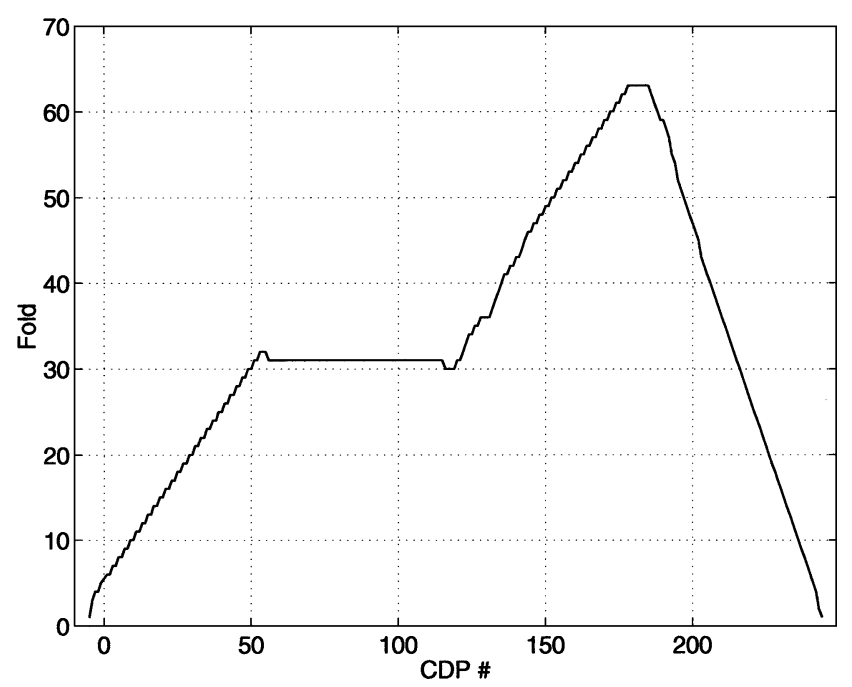

FIG. 2. CMP fold for the 120-receiver RAST acquisition procedure. The diagram is taken from the coastal plain survey.

\section{Fluvial environment}

A 240-m RAST profile was acquired at an agricultural test site in Burleson County, Texas (Sananikone and Everett, 1997), in cooperation with the Department of Geology and Geophysics at Texas A\&M University (Figure 1). The field site provides an ideal setting for a controlled experiment with wellcharacterized stratigraphy (Sananikone and Everett, 1997), $d_{W}=9 \mathrm{~m}$, and a shallow aquiclude $(\approx 20 \mathrm{~m})$ with a large acoustic impedance contrast with the overlying unconfined aquifer. The shallow $(<20 \mathrm{~m})$ Holocene sediments are fluvial in nature (point-bar sequence), having been deposited in the Brazos River Valley. In the Holocene sediments, a potentially significant impedance boundary occurs at a depth of $\sim 6 \mathrm{~m}$, where overlying flood-plain clays contact fluvial sand (CS). The fluvial sand coarsens with depth and contacts Tertiary shale of the Yegua Formation (SH) at a depth of about $20 \mathrm{~m}$ (Figure 3). The data set provides a good example of total masking of primary reflections inside the $W$ traveltime curve (Figure 4).

We acquired the coarse ( $2 \mathrm{~m}$ source and receiver spacing) survey to determine how well the slow, shallow, vadose zone and fast, deeper, saturated zone could be imaged using a single reflection survey. The roll-along portion of the profile was acquired with a $20-40$ split-spread configuration. The source was a 16-lb sledgehammer and steel plate with 12 hammer blows at each source location. The source/near-receiver gap was $\sim 0.1 \mathrm{~m}$.

We can identify $W$ at near offsets and the SH reflector outside the $W$ traveltime curve (Figure 4). The water table is clearly evident with a 50-100-200-350 bandpass filter, although it is obscured within the $140-\mathrm{m} / \mathrm{s}$ groundroll cone. We can identify $W$ to a minimum offset of about $6 \mathrm{~m}$ (Figure 4a). The critical angle is reached at an offset of about $4 \mathrm{~m}$, so the entire observed portion of $W$ is postcritical, although the phase rotation with increasing offset is not obvious. The $\mathrm{SH}$ reflection is best observed after muting inside $W$ and filtering with a 60-120-240-350 bandpass (Figure 4b). The shale reflection is clearly differentiable from the water table refraction $\left(H_{W}\right)$ in an offset range from 36 to $64 \mathrm{~m}$. Beyond this offset, the $H_{W}$ and $\mathrm{SH}$ events converge. Fortunately, in this case, the reflection amplitude is significantly larger than the refraction amplitude. Most of the far-offset energy can be confidently identified as reflected energy and can safely be used in imaging.

In processing these data, we use the two-pass approach, where the low- and high-velocity fields are imaged separately and then combined to produce the final depth profile. To process the low-velocity field, we apply an inside mute below the $W$ reflection and an outside mute at the direct arrival at about $420 \mathrm{~m} / \mathrm{s}$. Bradford (1998) derives a starting velocity model through traveltime inversion of shot gathers located along the profile. For migration of the low-velocity field, the velocity model is modified to assume constant, low velocity across and well below the water table. $W$ is flattened effectively across the profile with a 1-D velocity function (Figure 5a).

We prepare the data for processing the high-velocity field by applying an inside mute at the $420-\mathrm{m} / \mathrm{s}$ direct arrival cone and a top mute to the water table refraction. We use the full velocity field from inversion as a starting model. To get good migration results (Figure $5 \mathrm{~b}$ ), we reduce the velocity in the saturated sand from 1710 to $1600 \mathrm{~m} / \mathrm{s}$ (about $6 \%$ ). When migrated with the full velocity field, a significant amount of migration noise is generated at the sharp boundary between the low- and high-velocity 
fields. This can be reduced by smoothing the velocity field, but this comes at the cost of reducing accuracy. Our approach is to apply a top mute just below $d_{W}$, which, in the case of processing only the high-velocity field, contains only noise.

Combining the low- and high-velocity field stacks results in a good-quality image of $W$ and $S H$ (Figure 6a). $W$ is clearly imaged at a depth of just under $10 \mathrm{~m}$, and $S H$ is at a depth of about 18 to $20 \mathrm{~m}$, is consistent with stratigraphic descriptions. A significant amount of migration noise is present above $W$. We did not top mute the low $v$-field CIPs prior to stacking in the hope that the $C S$ reflection would stack coherently. While there may be some hint of a shallower reflection at $6 \mathrm{~m}$, it is masked by migration noise. The data presented here are migrated without an antialiasing filter because this results in the cleanest image of $W$. Applying an antialiasing filter does attenuate the migration noise above $W$, but a definitive interpretation of the $C S$ reflector is still impossible.

The image has an odd appearance with a very large difference in the length of the wavelet reflected from the water table compared with that from the aquitard. This difference indicates the physical increase of wavelength with increasing velocity and is not a processing artifact. The width of the $W$ wavelet is about $4 \mathrm{~m}$, whereas the width of the $S H$ wavelet is about $18 \mathrm{~m}$. This gives a wavelet length ratio of 4.5. The wavelet length is roughly proportional to the wavelength at the peak frequency. Since the wavelength is directly proportional to the velocity, the predicted wavelength ratio is $\lambda_{\text {fast }} / \lambda_{\text {slow }}=v_{\text {fast }} / v_{\text {slow }}=$ $1600 / 383=4.18$. Thus, the observed ratio is very close to the predicted ratio. The slightly larger value for the wavelet length ratio can be attributed to differential stretch of $S H$ versus $W$ with increasing offset.

For comparison, $S H$ was processed independently using NMO and stacking followed by Dix inversion and depth conversion (Figure $6 \mathrm{~b}$ ). The top of $S H$ appears at depths that range from about 25 to $32 \mathrm{~m}$, which gives a maximum error of $\delta d_{S H}=14 \mathrm{~m}\left(\sigma_{S H} \approx 80 \%\right)$. This is a significant error and would
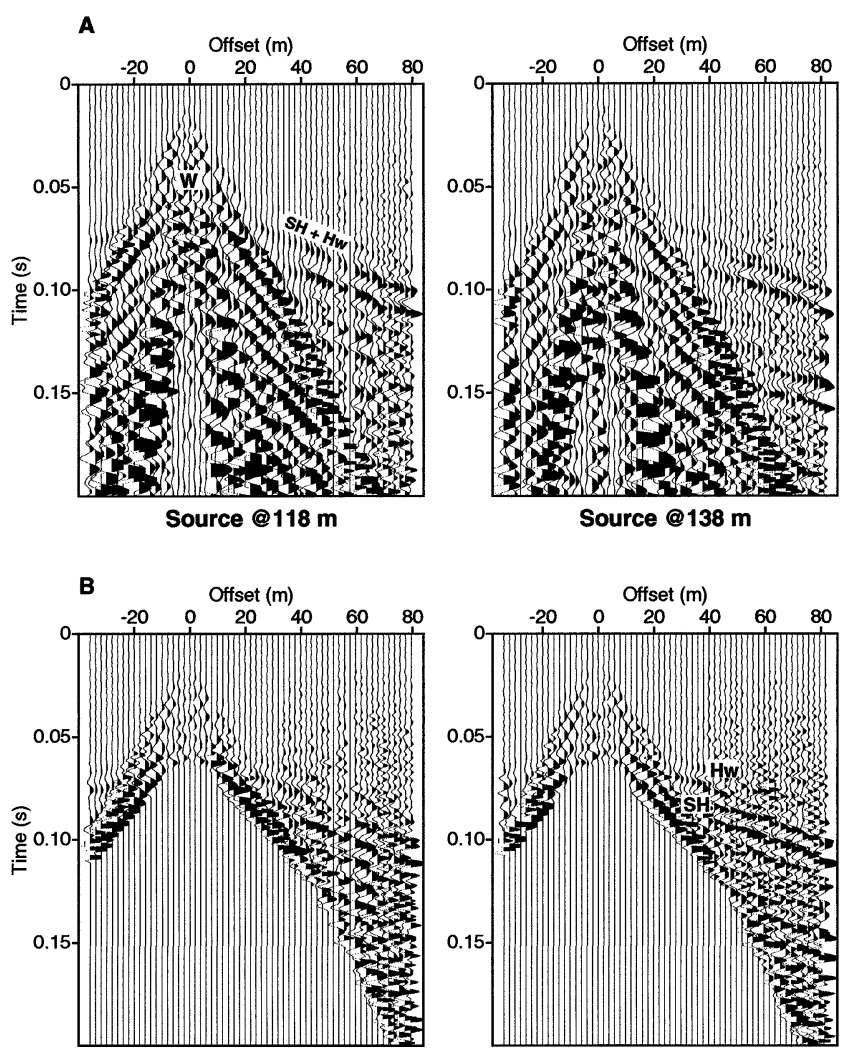

FIG. 4. Representative shot gathers from the coarse survey at the Burleson County site (a) with a low cut of (a) $50 \mathrm{~Hz}$ and (b) $60 \mathrm{~Hz}$. The lower passband better preserves energy from $W$, while filtering at the higher passband helps resolve the aquitard reflector, $S H$, which is roughly $10 \mathrm{~m}$ below the water table. The entire portion of $W$ that is visible is postcritical, but phase rotation is not obvious. The frequency content is lower for the shot at $118 \mathrm{~m}$, and $S H$ is not as well resolved as it is in the shot at $138 \mathrm{~m}$.

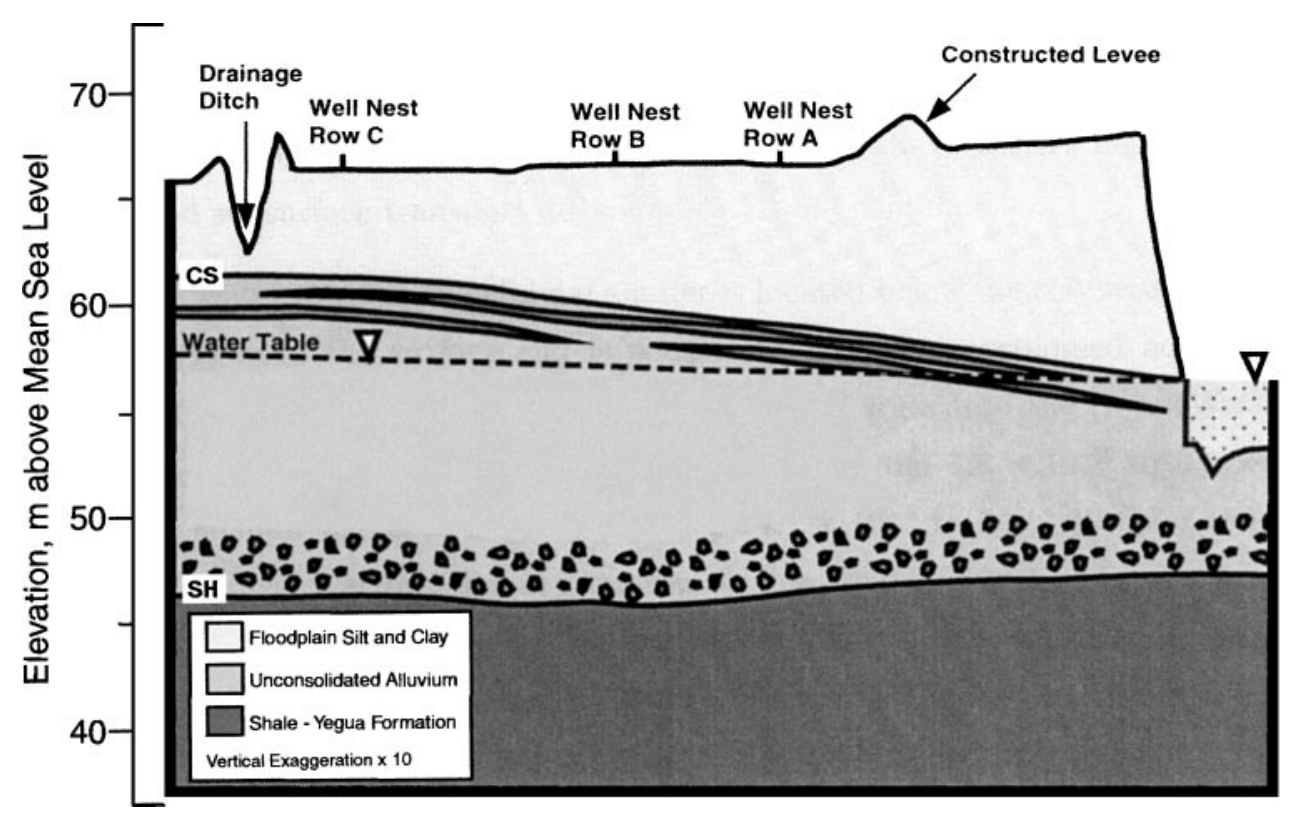

FIG. 3. Cross-section from the Burleson County site. Modified from Sananikone and Everett (1997). 
be unacceptable for many applications. Comparison of the interval velocity obtained via Dix inversion with that obtained through migration velocity analysis shows that Dix inversion significantly overpredicts interval velocity in the saturated zone (Figure 7). Note that differential stretch of the $S H$ reflector relative to deeper wavelets is primarily related to the interval velocity function used for depth conversion. The Dix interval velocity between $W$ and $S H$ is significantly larger than the estimate deeper in the section, so the $S H$ wavelet appears broader.

\section{Coastal plain environment}

As a field exercise for the exploration geophysics class at Rice University, we acquired a 240-m RAST survey across a soccer/rugby field on the Rice campus (Figures 1 and 8 ). The roll-along portion of the profile was acquired in off-end mode with a source/near-receiver gap of $10 \mathrm{~m}$. The shoot-through portion of the profile was acquired with a gap of $\sim 0 \mathrm{~m}$. The source was a 16-lb sledgehammer and plate with 12 hammer blows recorded at each source station. Source and receiver station

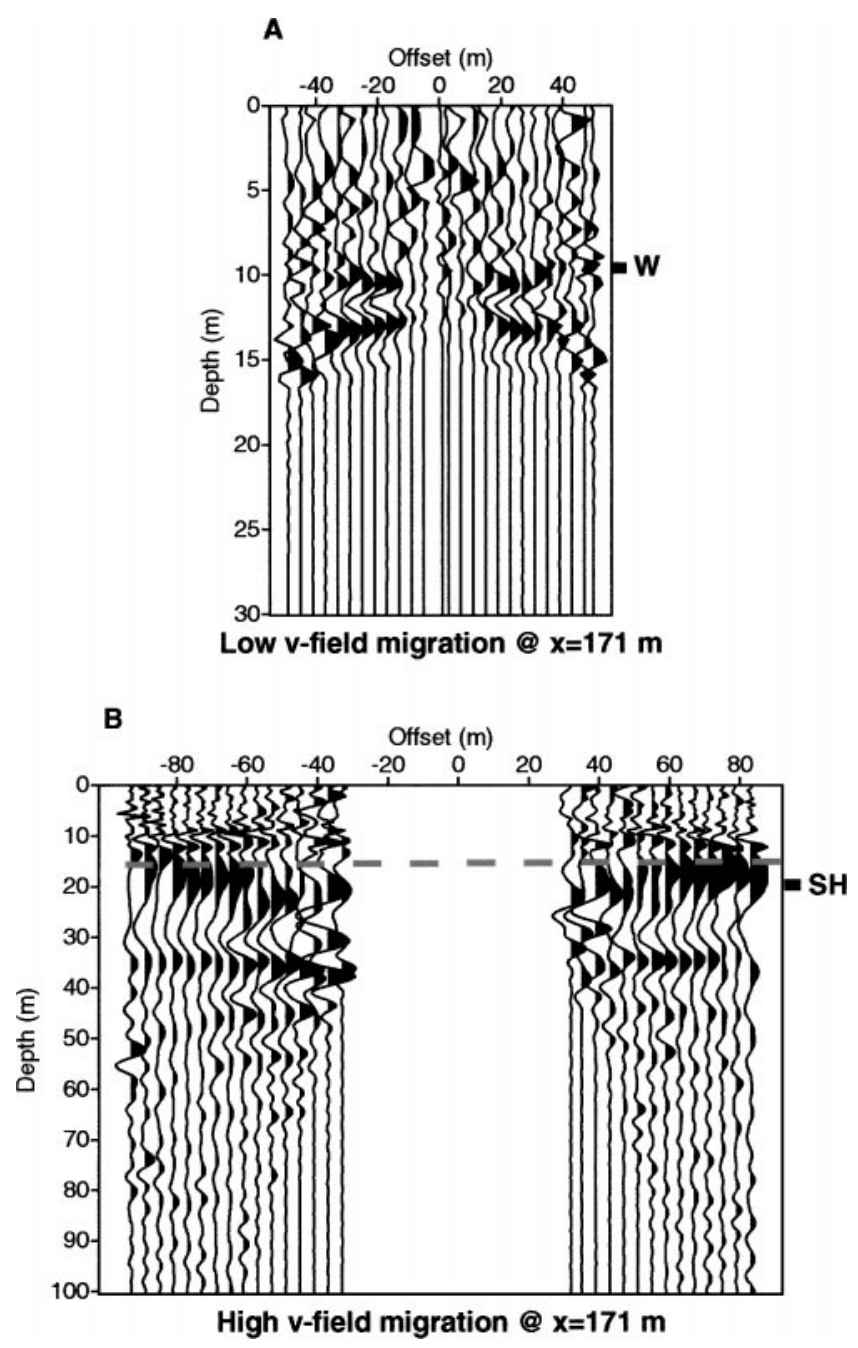

FIG. 5. CIP171 after migration of the low-velocity field (a) with a partial velocity function and the high-velocity field (b) with the full velocity function (note difference in depth scale). Both $W$ and $S H$ are flattened across the range of offsets where they are visible. The dashed line indicates top mute position.
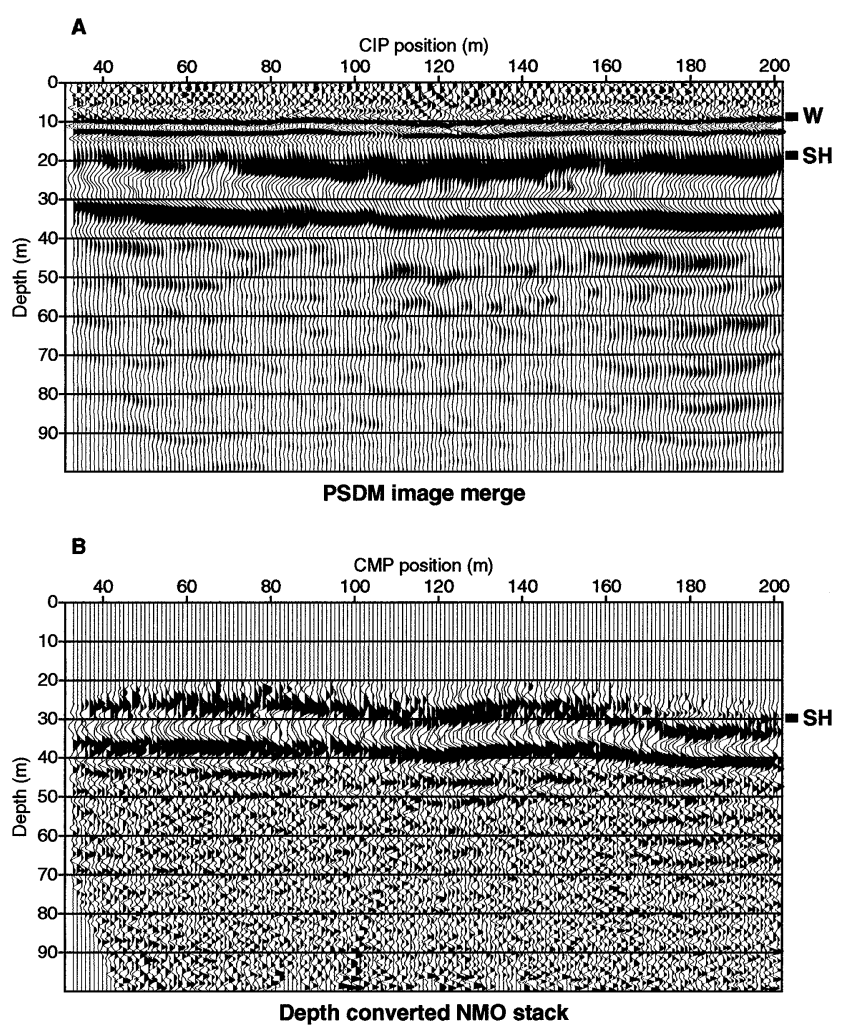

FIG. 6. A PSDM image after merging the low- and high-velocity fields (a) and depth-converted stack using velocities from Dix inversion (b). In the PSDM image, $W$ and $S H$ are consistent with known depths to the water table and shale aquitard. The stretch of $S H$ corresponds to the velocity increase in the saturated zone. Depth to $S H$ in (b) is significantly overpredicted. Apparent variations in wavelength with depth in (b) are primarily related to errors in the interval velocity model used for depth conversion.

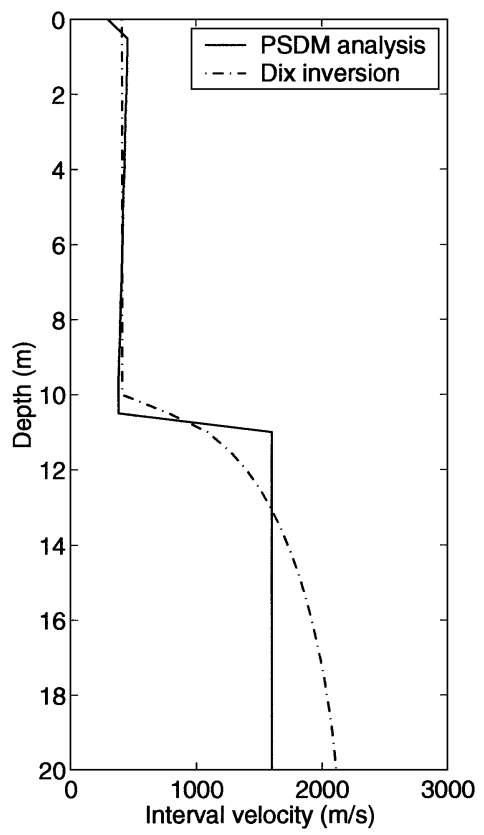

FIG. 7. Comparison of velocity models derived through PSDM velocity analysis and Dix inversion. Dix inversion significantly overpredicts the velocity below the water table. 


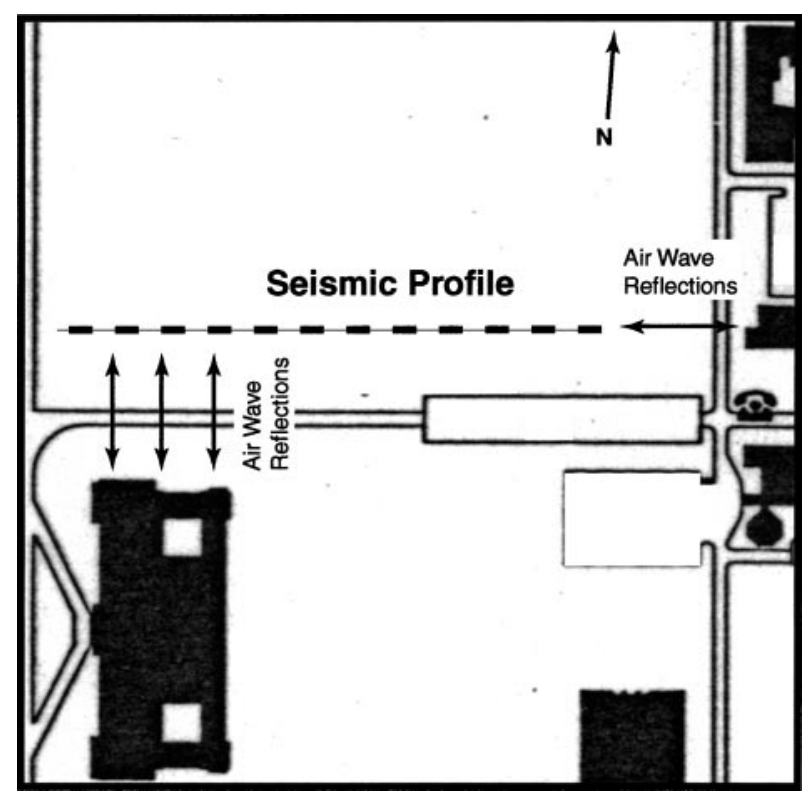

FIG. 8. Location of the Rice profile and position relative to campus buildings. Air-wave reflections from the buildings are a major source of coherent noise at later times (Figure 9).

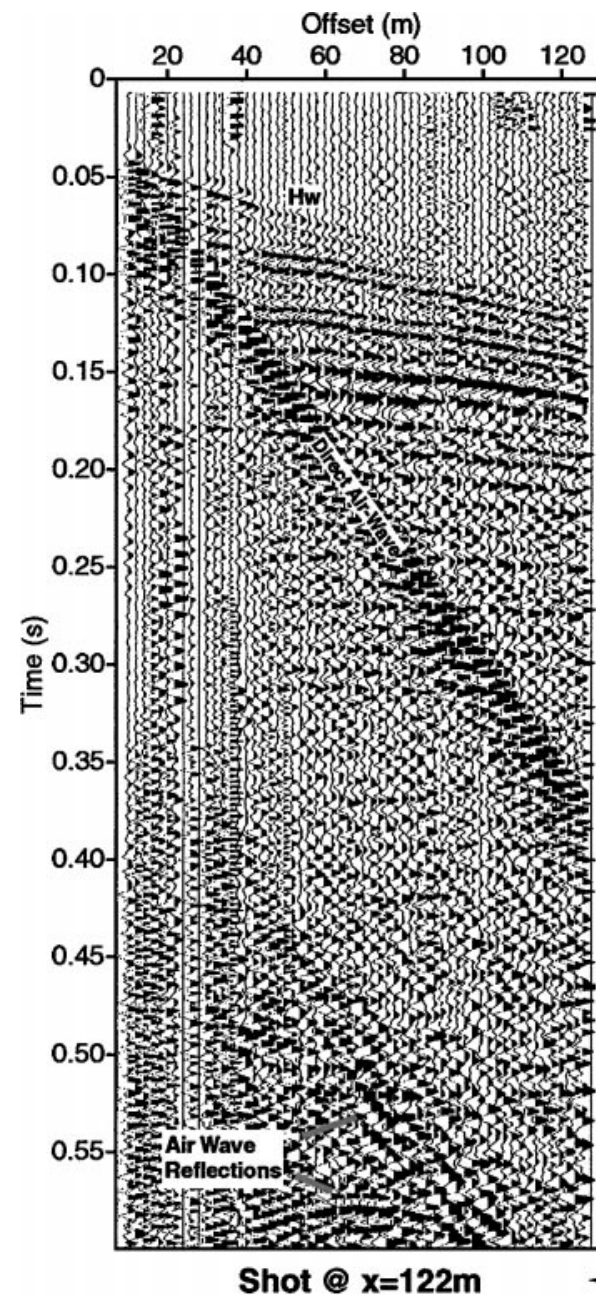

intervals were $2 \mathrm{~m}$. The surface sediment consists of dense clay of the Pleistocene-age Beaumont Formation, providing excellent source and receiver coupling. The stratigraphy consists of interbedded sands, gravels, and shales of variable thickness to a depth of least $454 \mathrm{~m}$. Stratigraphic information was obtained from the description of a deep water well boring located several hundred meters from the reflection profile. The shallow stratigraphy $(<30 \mathrm{~m})$ near the reflection profile does not match that in the location of the deep boring, but the general lithologic composition is similar.

The data are of exceptional quality, and reflections are evident to around $500 \mathrm{~ms}$ (Figure 9). A temporally and spatially varying band-pass filter was applied to the shot gathers to minimize low-frequency ground roll. This varied from 70-140-280460 at near offsets and small times to 30-60-120-240 at the maximum time displayed, $600 \mathrm{~ms}$. All data displayed have been corrected for spherical divergence and gained to the first power of $t$. A high-amplitude air wave and ground roll at a maximum phase velocity of about $140 \mathrm{~m} / \mathrm{s}$ are the primary sources of coherent noise (Figure 9). Deep reflections are clearly observed inside the air-wave cone, but primary reflection energy cannot be extracted below $W$ at offsets less than about $14 \mathrm{~m}$. The scatter below $500 \mathrm{~ms}$ is an air-wave reflection from the corner of a building located adjacent to the west end of the line (Figures 8

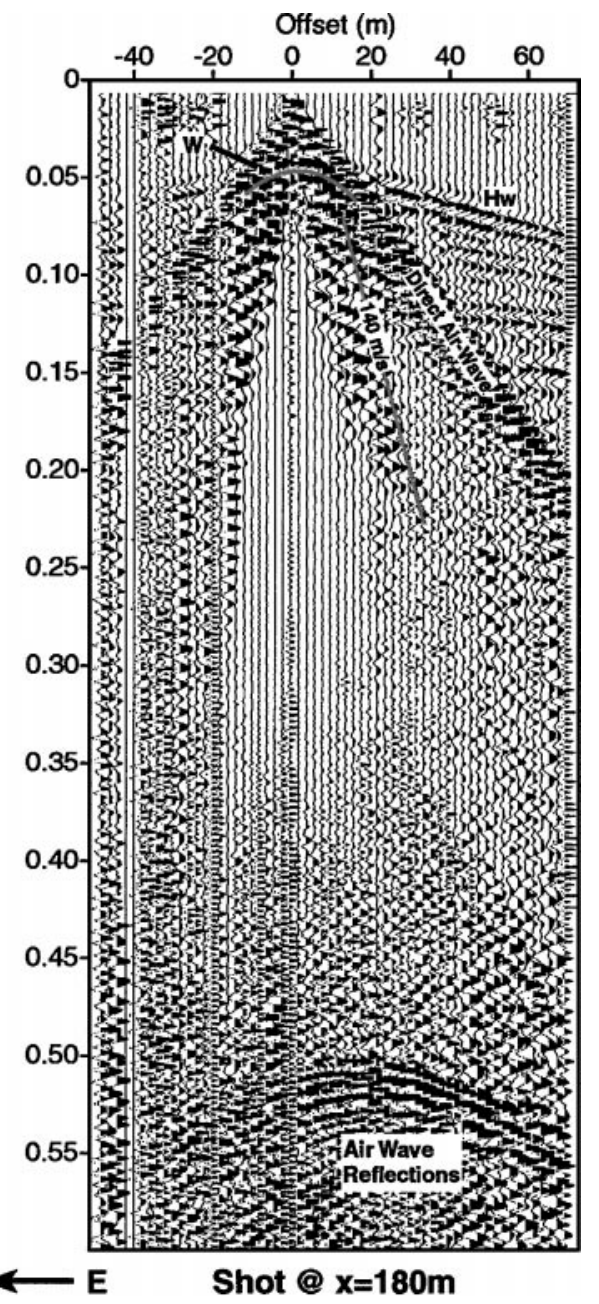

FIG. 9. The data quality at the Rice site is excellent; the water table reflection is clearly identified, and primary reflections deeper than $500 \mathrm{~ms}$ are evident. Air-wave reflections from buildings interfere with deeper primary reflections. 
and 9). Linear coherent noise below $400 \mathrm{~ms}$ on the east end of the profile is an off-end air-wave reflection from a second building (Figures 8 and 9). $W$ is clearly evident in the nearoffset portion (west) of the profile, and reflected energy can be identified to a minimum offset of about $2 \mathrm{~m}$ on the best shot gathers (Figure 9). The quality of $W$ is variable and is totally obscured by ground roll on some records. $W$ is not present in the far-offset (east) records.

NMO processing.-Assuming $W$ can be imaged accurately using NMO and stacking and that the best image will be obtained by processing all data deeper than $W$ with a partial stacking velocity field (excluding $\left.v_{s t k}\right|_{W}$ ) in a separate processing pass, we do not include $W$ in the NMO analysis. The processing flow includes filtering, spherical spreading correction and scaling by $t$, semblance velocity analysis, correlation autostatics, NMO corrections, and stacking (Figures 10 and 11). The full stacking velocity field, including $\left.v_{s t k}\right|_{w}$, was used in depth conversion. The stacked section is of good quality to a depth of about $400 \mathrm{~m}$ (Figure 10a). Reflections can be identified clearly to about $600 \mathrm{~m}$ in the center of the section. The data quality de-
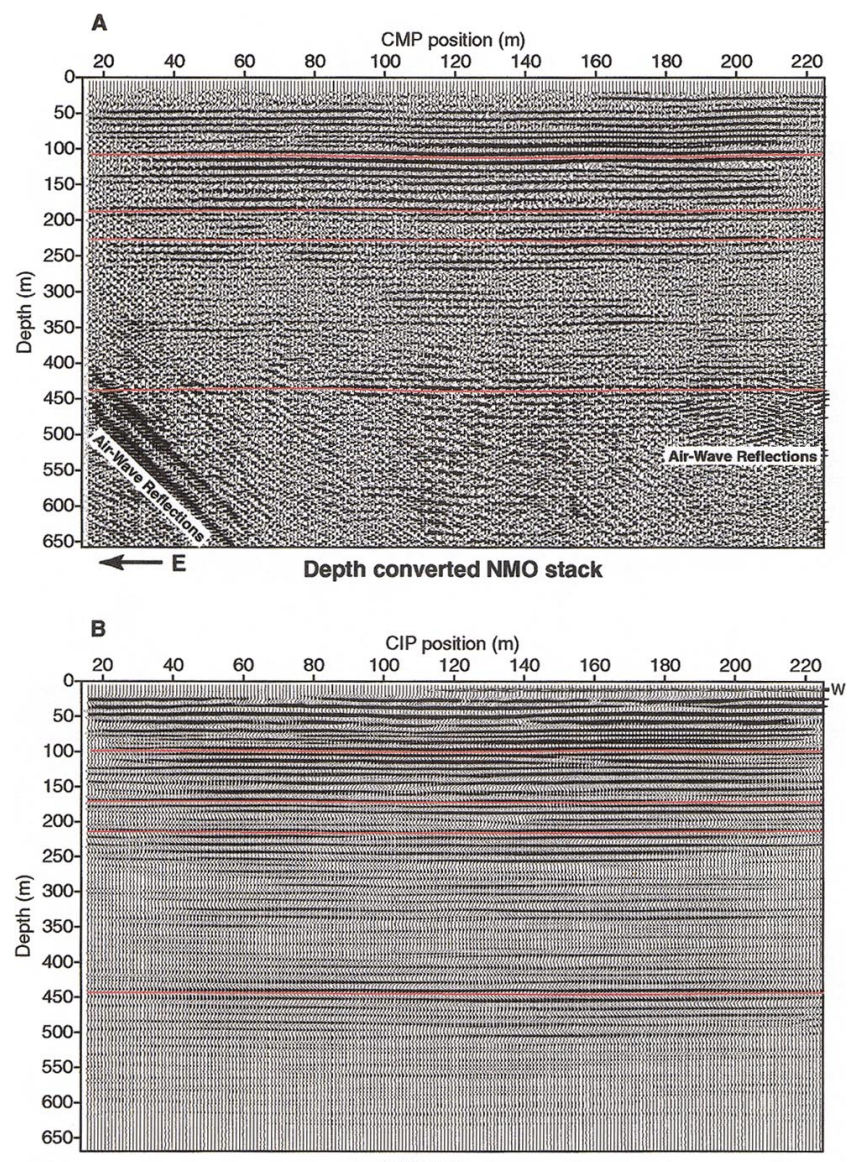

PSDM image

FIG. 10. Rice profile after NMO, stacking, and depth conversion (a) and a PSDM image (b). Red lines indicate reference reflectors. Significant differences in depth are evident to about $250 \mathrm{~m}$. PSDM significantly reduces random noise and effectively attenuates coherent air-wave reflections deep in the section. creases as fold drops off near the ends of the profile. Air-wave reflections contaminate the east side of the profile at depths from 400 to $650 \mathrm{~m}$ and the west side at depths from 450 to $550 \mathrm{~m}$.

PSDM processing.-We prepare the data by muting the faroffset tails of the water table reflection, muting everything below $W$ at offsets $<32 \mathrm{~m}$, and applying a top mute to remove the first arrival, which is the direct wave at near offsets and the water table refraction at far offsets. The air blast is removed with a surgical mute. The starting velocity model is obtained by the two-layer method, and the full data field is migrated using the one-pass strategy. Four iterations of PSDM velocity analysis produce good migration results (Figures 10-12) with a relatively simple 1-D velocity model (Figure 13). We find that applying statics corrections prior to migration significantly improves velocity analysis convergence and the migration result. It should be noted that velocity statics can be handled correctly during depth migration, thereby eliminating statics corrections as a data conditioning step (Rajasekaran and McMechan, 1992). However, this requires building a detailed shallow-velocity model using tomographic techniques.

Stacking the migrated CIPs produces a high-quality depth image with several qualitative improvements from the NMOprocessed sections (Figures 10 and 11). The air-wave reflections have been efficiently suppressed and are not evident either on the left or right side of the section. Through PSDM processing,
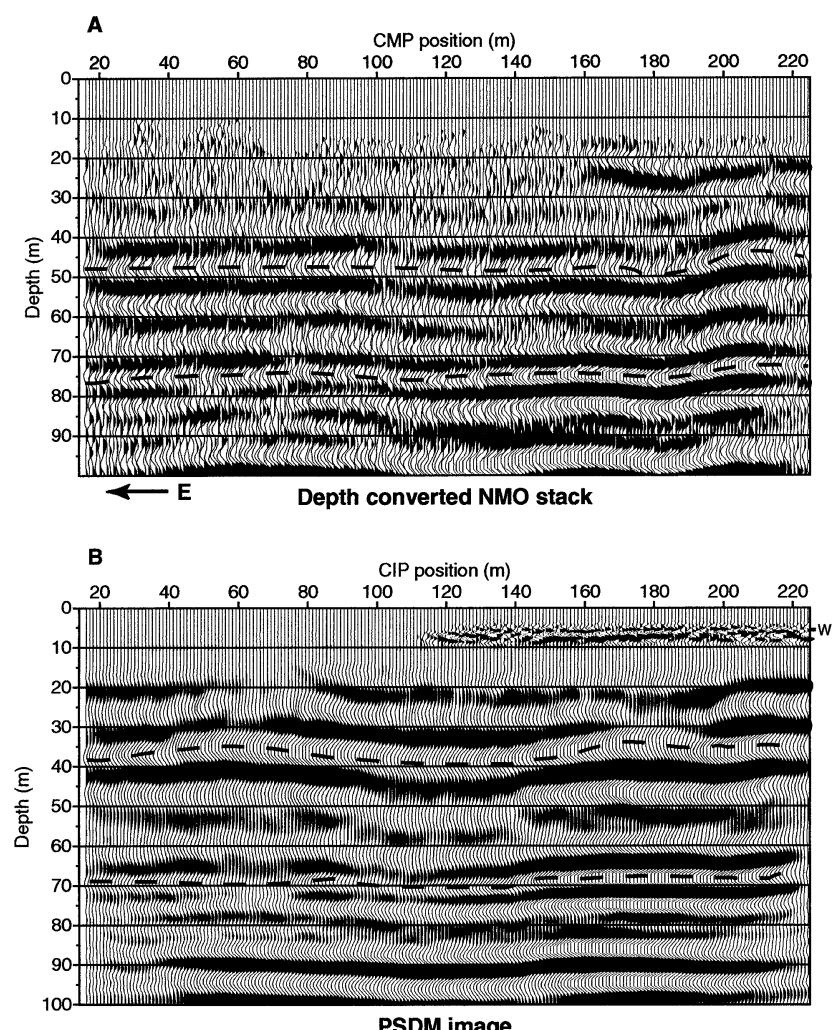

FIG. 11. Shallow portion of the Rice profile after NMO, stacking, and depth conversion (a) and a PSDM image (b). Reference reflectors are shown with dashed lines. All reflectors below $W$ are overestimated by about $10 \mathrm{~m}$ in the NMO section. $W$ only migrates coherently from about $x=140-200 \mathrm{~m}$. It is not shown in the NMO section. 
the full section has been imaged in a single pass, from the water table reflection to the deepest reflection we can pick with confidence, at around $550 \mathrm{~m}$.

The quality of $W$ varies significantly along the line (it is not present on the east side of the profile) but is clear at a depth of around $6 \mathrm{~m}$, from about 145 to $190 \mathrm{~m}$ (Figure 11b). The quality of this reflector is best where the fold is highest along the line. However, since $W$ is confined to near offsets, the change in data quality cannot be attributed to decreased fold. The effective fold (number of traces per CMP that actually have energy from $W$ ) remains essentially constant from 120 to $230 \mathrm{~m}$. The decrease in reflector quality is the result of data quality variations and is not related to the change in fold. This case could likely be improved significantly with denser source and receiver spacing.

For a quantitative comparison of the Dix inversion and PSDM results, consider the shallowest $100 \mathrm{~m}$ of the PSDM and depth-converted NMO profiles (Figure 11). All of the reflectors in the PSDM section are roughly $10 \mathrm{~m}$ shallower than the corresponding events in the NMO-processed section. The depth estimate error, resulting from NMO processing and Dix inversion, is about $50 \%$ for the shallowest reflector, then is proportional to $1 / d$, and is around $11 \%$ for the deepest reflector at a depth of about $90 \mathrm{~m}$.

Velocity model comparison.-The most interesting feature of the velocity model is the sharp velocity inversion from about

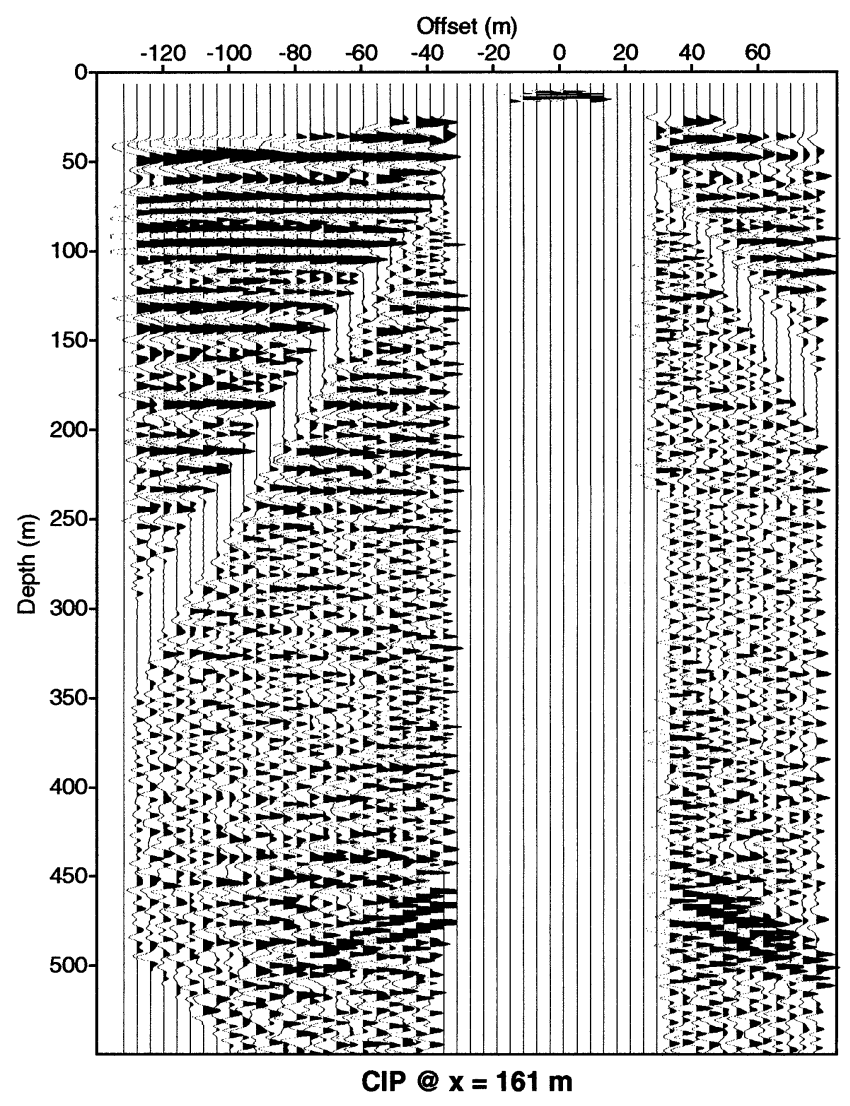

FIG. 12. CIP 161 after PSDM of the full section. All reflections in the CIP are flattened. The strong reflection at $450 \mathrm{~m}$ is evident in this CIP. Strong, coherent noise events from 450 to $550 \mathrm{~m}$ are out-of-plane air-wave reflections.
65 to $105 \mathrm{~m}$ (Figure 13 ). The velocity in this region is just slightly greater than water velocity, and we speculate that this is related to the inclusion of trapped gas in the pore space of a sand unit, which may be a fairly common occurrence in shallow, confined aquifers (Bradford et al., 1997). AVO analysis along this reflector has the potential to provide additional insight on the nature of the low-velocity zone (Bradford et al., 1997) but has not yet been performed with this data set, although it is a good candidate given the quality of the data.

The Dix inversion model has dramatic oscillations between 5 and $40 \mathrm{~m}$ (Figure 13). There is some indication of a velocity inversion between 65 and $100 \mathrm{~m}$, but it is not well defined and the magnitude of the velocity change is significantly less than estimated with PSDM velocity analysis. Below about $105 \mathrm{~m}$, Dix inversion and migration velocity analysis give virtually identical results. Computation requirements could be minimized by processing only the shallower portion of the section with PSDM and using standard NMO processing to image the deeper $(>100 \mathrm{~m})$ portion of the profile. This would come at the cost of reduced noise suppression but should provide sufficient accuracy.

\section{Coastal environment}

We acquired a 30-fold, 1-km profile on Bolivar Peninsula near Galveston, Texas (Figure 1). The experiment's objective was to determine how well we could image the strata of an incised valley-fill sequence to a depth of about $50 \mathrm{~m}$ (Figure 14). Holocene sedimentary strata at the site (Figure 14) consist of medium- to fine-grained barrier island sands to depths varying from 5 to $10 \mathrm{~m}$, fine-grained bay sediments from $\sim 8$ to $\sim 25 \mathrm{~m}$, and fluvial sand from $\sim 25$ to $\sim 50 \mathrm{~m}$, which is the maximum depth of the Trinity River incision at this location. The incision

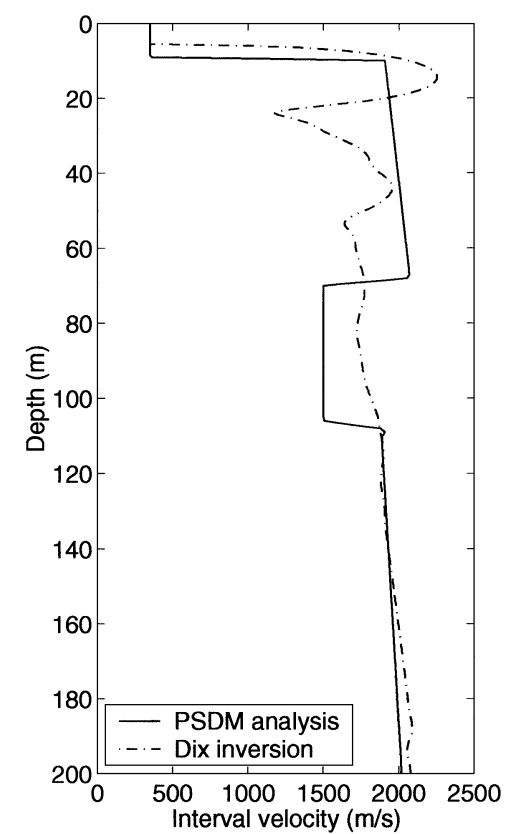

FIG. 13. Velocity models determined from Dix inversion and PSDM velocity analysis. Dix inversion velocities are a poor representation of the velocity field above $120 \mathrm{~m}$. The velocity models are nearly identical below $110 \mathrm{~m}$. 
cuts into older Pleistocene clays. The water table is relatively shallow, at a depth of only $3 \mathrm{~m}$.

The data were acquired with 2-m source and receiver spacing, a source/near-receiver gap of $\sim 0 \mathrm{~m}$, and 30-30 split-spread geometry. The source was a 16-lb sledgehammer and steel plate with four hammer blows stacked at each source point. A peak frequency of about $120 \mathrm{~Hz}$ could be extracted in the filtered shot gathers, which showed good-quality reflection to about $130 \mathrm{~ms}$ (Figure 15). We could not extract primary reflections inside the $330-\mathrm{m} / \mathrm{s}$ air-wave cone and applied an inside mute to suppress noise in this region.

A velocity model was constructed using the traveltime inversion method of Zelt and Smith (1992) based on picks of both first arrivals and reflections (Bradford et al., 1997). A low-velocity zone is present in the fluvial sand unit which fills the lower $25 \mathrm{~m}$ of the incision. Previous AVO work suggests that the anomalously low velocity in the sand unit is likely from partial gas saturation of the pore space. For clarification of the interpretation and discussion of the full data set, refer to Bradford et al. (1997).

A $170-\mathrm{m}$ portion of the $1-\mathrm{km}$ line is discussed in this analysis (Figure 16). The data were migrated using a 1-D velocity function derived from local smoothing of the inversion velocity model (Figure 17). This yields acceptable results without additional PSDM velocity analysis (Figure 16a). A fully processed NMO-stacked, depth-converted section is included for comparison (Figure 16b). Prior to stacking, dip moveout (DMO) was applied to the NMO section. Residual statics corrections were applied to both the PSDM and NMO sections.

The water table is very shallow $(\sim 3 \mathrm{~m})$, and $W$ is not imaged in either the PSDM or the NMO section. The most important difference in the shallow part of the section is that the baseof-barrier reflection at a depth of about 6 to $8 \mathrm{~m}$ is imaged reasonably well in the NMO section but is poorly imaged in the migrated section. This is attributed primarily to migration noise in the shallower part of the section. This boundary appears at a depth of about $6 \mathrm{~m}$ in the migrated section, compared with $8 \mathrm{~m}$ in the NMO section. This is a variation of about $33 \%$ but is a minimal difference compared to the $13-\mathrm{m}$ wavelength at the peak frequency of $120 \mathrm{~Hz}$. Each of the other reflectors in the section down to the bright top-of-fluvial sand reflector at about $25 \mathrm{~m}$ is also placed about 2 to $3 \mathrm{~m}$ deeper in the NMO section. This is a minimum depth error of about $12 \%$ for the top-of-sand reflector. The more significant difference in precision becomes evident when examining the base-of-incision reflection at about $50 \mathrm{~m}$. This reflection is about $5 \mathrm{~m}$ deeper in the NMO section. This is only about a $10 \%$ error in depth but is roughly a $100 \%$ increase in $\delta d$ relative to the shallower reflections. Traveltime inversion indicates that the average velocity across the velocity inversion is about $1170 \mathrm{~m} / \mathrm{s}$, while Dix inversion predicts an average velocity of $1300 \mathrm{~m} / \mathrm{s}$ (Figure 17). So depth conversion with the Dix interval velocities adds an additional 3-4 $\mathrm{m}$ to $\delta d$. However, this error is still relatively small compared to the wavelength, the depth to the reflector, and the relative error observed for reflectors near the water table.

Comparing the traveltime inversion and Dix inversion velocity models (Figure 17), we see a striking difference relative

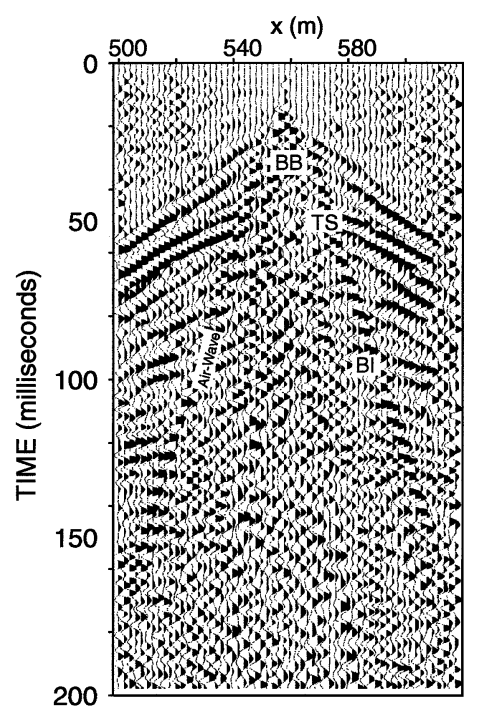

FIG. 15. Representative shot gather from the Bolivar Peninsula survey. Base of barrier sands (BB), top of fluvial sand (TS), and base of incision (BI) are labeled. The $x$ indicates the receiver position in the survey.

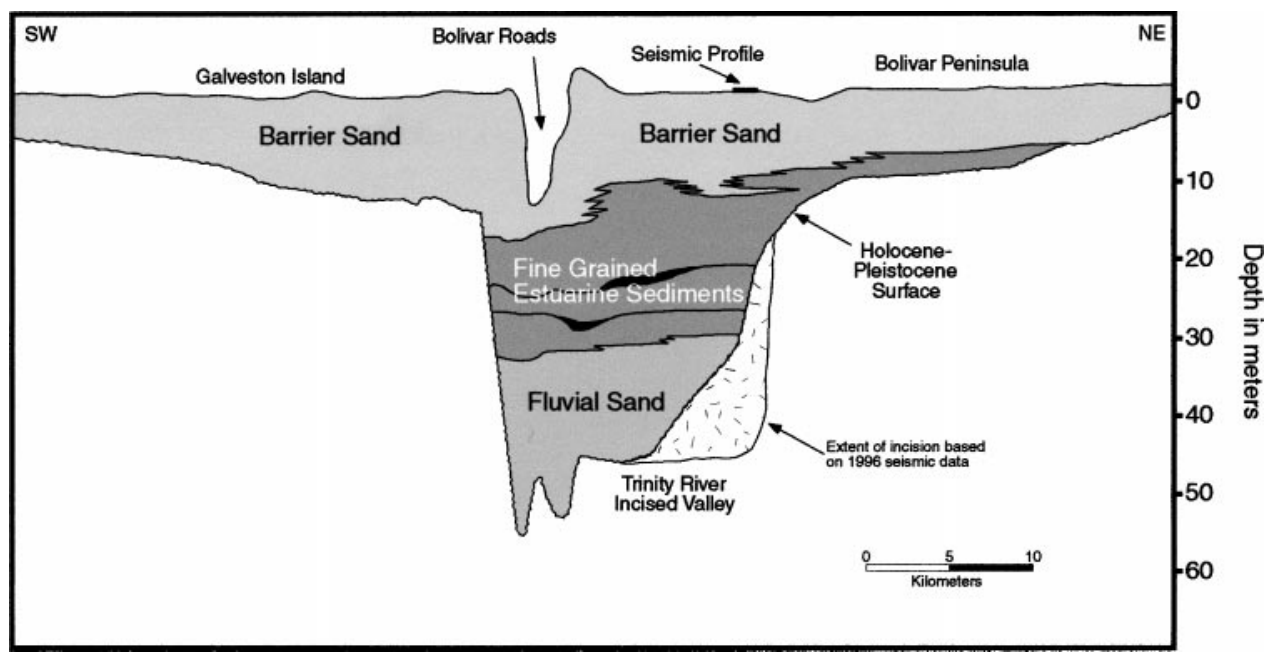

FIG. 14. Cross-section of the Trinity River incised valley. Adapted from Siringan and Anderson (1993). 
to the fluvial and coastal plain examples. In this case, Dix inversion actually underpredicts the velocity contrast across the water table and appears to represent running average interval velocity for the full thickness of the section. The velocity contrast across the water table is underpredicted because we did not include the low-velocity vadose zone in the Dix inversion. This results in a reasonable velocity function only because the vadose zone is very thin. Bradford (2002) shows that velocity bias decreases rapidly when the thickness of the low-velocity zone is less than about $5 \mathrm{~m}$.

The more interesting difference in this example is qualitative in nature. The strata at this site are more complex than either the fluvial or coastal plane examples. In this case, we have dipping and truncated reflectors, providing a good example of the additional detail that may be extracted by applying PSDM, as opposed to performing traveltime inversion to derive a gross depth and velocity structure. In particular, a set of dipping reflectors between $x=40$ and $100 \mathrm{~m}$ has have been truncated by the fluvial incision at a depth of about $50 \mathrm{~m}$ (Figure 16a). The dipping strata appear to be part of an older depositional feature that included multiple levels of erosion. The truncated reflec-
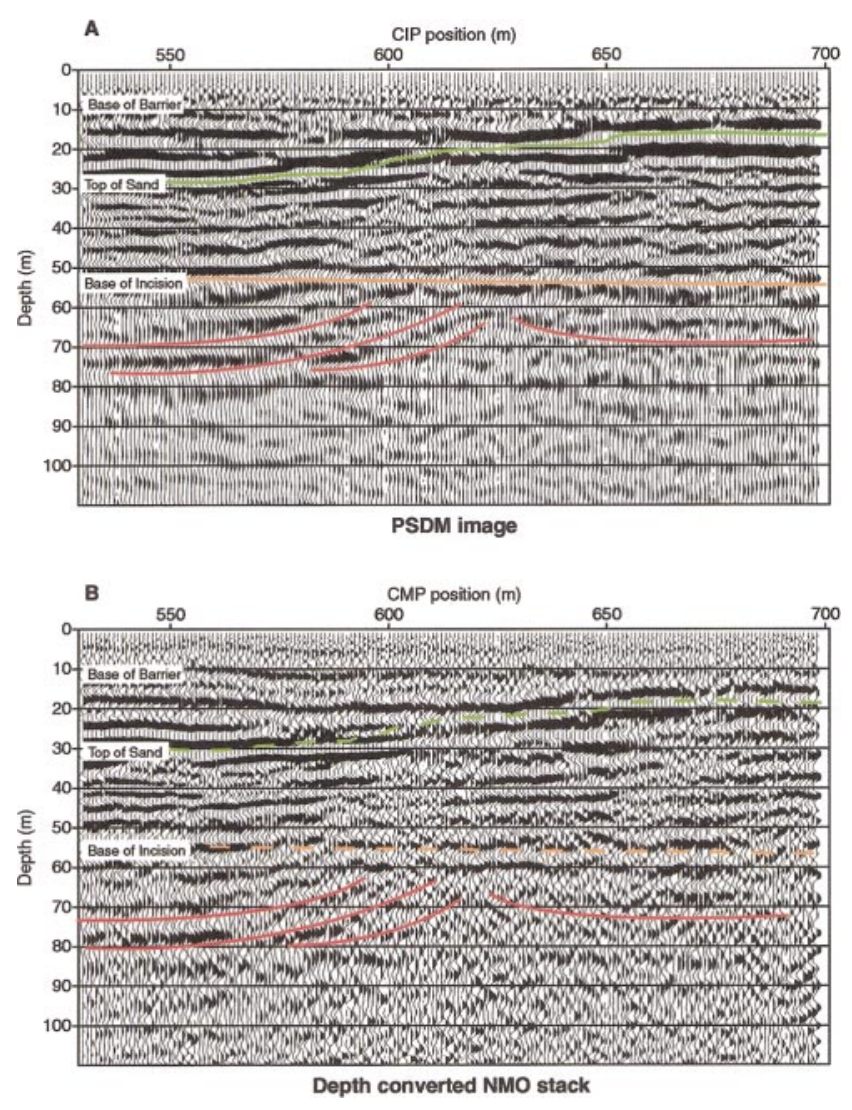

FIG. 16. PSDM image (a) and NMO stack with depth conversion (b) of a portion of the Bolivar Peninsula profile. In this case, the depth prediction error from Dix velocities is relatively small (green and orange dashed lines on the NMO stack indicate interpreted depths from the PSDM image). The dipping reflectors (red) truncated by the incision (orange) are more clearly imaged with PSDM. Note that wavelength variation with depth is primarily related to the interval velocity model. [Refer to Bradford et al. (1997) for clarification of the interpretation and analysis of the full data set.] tors are imaged very clearly in the PSDM section. Although they are evident in the NMO section, they certainly are not clear, and the relationship indicating multiple levels of erosion cannot be discerned. The improved image can partially be attributed to noise suppression of the migration operator. More importantly, in heterogeneous media, PSDM properly handles reflector point dispersal associated with dipping reflectors and conflicting dips without the constant velocity assumption inherent in DMO processing. Through prestack migration, we have not only improved the accuracy of the final image but have brought out additional stratigraphic detail.

\section{CONCLUSIONS}

PSDM is the most accurate and detailed imaging tool available. Through field examples, we have illustrated that significant improvements in the accuracy of shallow reflection profiles can be made using PSDM processing. Currently, PSDM imaging is not commonly used in shallow seismic reflection studies. This may be largely because of economics. Environmental seismology is constrained by financial limitations to a much greater extent than the oil industry. But as computing costs continue to decrease while computing power increases, it will become feasible to include prestack depth migration as a standard tool available to the environmental seismologist. PSDM is typically reserved for areas with large lateral velocity variations. However, in some cases it is also valuable where there are very large vertical velocity contrasts. Although there are less computationally intensive methods for solving the problem, they will provide less detailed images than PSDM.

\section{ACKNOWLEDGMENTS}

This work was partially funded under the EPA STAR program. We thank Alan Levander and John Anderson of Rice

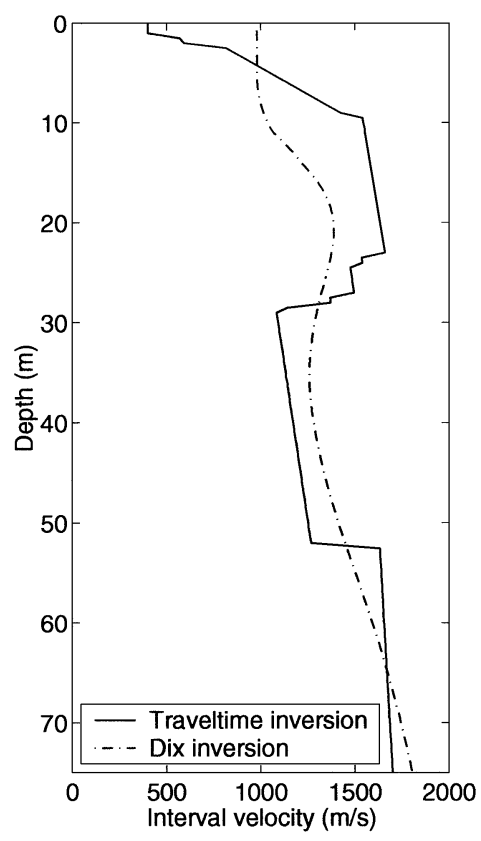

FIG. 17. Velocity functions derived for the Bolivar profile. In this case, the Dix velocities are a reasonable representation of the average interval velocity. 
University for use of the seismograph and geophone array, which were purchased under NSF grant EAR-9316711. Additionally, we would like to thank Mark Everett and Veit Matt of Texas A\&M University for help with getting access to the hydrogeologic test site and all the students at Rice University who assisted with field work. We thank Don Steeples and his research group for reviewing the manuscript.

\section{REFERENCES}

Al-Chalabi, M., 1974, Analysis of stacking RMS average and interval velocities over a horizontally layered ground: Geophys. Prosp., 22, 458-475.

Al-Yahya, K. M., 1989, Velocity analysis by iterative profile migration: Geophysics, 54, 718-729.

Baker, G. S., Steeples, D. W., and Drake, M., 1998, Muting the noise cone in near-surface reflection data: An example from southeastern Kansas: Geophysics, 63, 1332-1338.

Bradford, J. H., 1998, Characterizing shallow aquifers with wavepropagation based geophysical techniques: Imaging and attribute analysis: Ph.D. thesis, Rice University.

2002, Depth characterization of shallow aquifers with seismic reflection, part I-The failure of NMO velocity analysis and quantitative error prediction: Geophysics, 67, 89-97, this issue.

Bradford, J. H., Sawyer, D. S., and Zelt, C. A., 1997, AVO analysis of low-velocity, shallow sands $(<50 \mathrm{~m})$ : 67th Ann. Internat. Mtg., Soc. Expl. Geophys., Expanded Abstracts, 158-162.

Hunter, J. A., Pullan, S. E., Burns, R. A., Gagne, R. M., and Good, R. S., 1984, Shallow seismic reflection mapping of the overburden- bedrock interface with the engineering seismograph-Some simple techniques: Geophysics, 49, 1381-1385.

Lafond, C. F., and Levander, A. R., 1993, Migration moveout analysis and depth focusing: Geophysics, 58, 91-100.

Levin, S. A., 1998, Resolution in seismic imaging: Is it all a matter of perspective?: Geophysics, 63, 743-749.

Liu, Z., 1997, An analytical approach to migration velocity analysis: Geophysics, 62, 1238-1249.

Miller, R. D., 1992, Normal moveout stretch mute on shallow-reflection data: Geophysics, 57, 1502-1507.

Miller, R. D., and Xia, J., 1998, Large near-surface velocity gradients on shallow seismic reflection data: Geophysics, 63, 1348-1356.

Pasasa, L., Wenzel, F., and Zhao, P., 1998, Prestack Kirchhoff depth migration of shallow seismic data: Geophysics, 63, 1241-1247.

Rajasekaran, S., and McMechan, G. A., 1992, A new approach to prestack seismic processing: 62nd Ann. Internat. Mtg., Soc. Expl. Geophys., Expanded Abstracts, 1030-1033.

Sananikone, K., and Everett, M. E., 1997, Characterization of the electrical structure of an agricultural field in Burleson County, TX: Symp. on Appl. of Geophys. to Eng. and Environ. Problems, Env. Eng. Geophys. Soc., Proceedings, 891-800.

Steeples, D. W., and Miller, R. D., 1990, Seismic reflection methods applied to engineering, environmental, and groundwater problems, in Ward, S. H., Ed., Geotechnical and environmental geophysics: Soc. Expl. Geophys., Investigations in Geophysics 5, 1-30.

1998, Avoiding pitfalls in shallow seismic reflection surveys: Geophysics, 63, 1213-1224.

Taner, M. T., and Koehler, F., 1969, Velocity spectra-Digital computer derivations and applications of velocity functions: Geophysics, 34, 859-881.

Zelt, C. A., and Smith, R. B., 1992, Seismic traveltime inversion for 2-D crustal velocity structure: Geophys. J. Internat., 108, 16-34. 